\title{
Development Characteristics and Causes of a Fatal Landslide Occurred in Shuicheng, Guizhou Province, China
}

\author{
Yu Chen ${ }^{1,2}$, Xiangli He ${ }^{1,3,4, *(\mathbb{D})}$, Chong Xu ${ }^{1,3,4} \mathbb{1}$, Yuandong Huang ${ }^{1}$, Pengfei Zhang ${ }^{5}$, Zhihua Luo ${ }^{2}$ \\ and Tao Zhan ${ }^{6}$
}

check for

updates

Citation: Chen, Y.; He, X.; Xu, C.;

Huang, Y.; Zhang, P.; Luo, Z.; Zhan, T.

Development Characteristics and

Causes of a Fatal Landslide Occurred

in Shuicheng, Guizhou Province,

China. ISPRS Int. J. Geo-Inf. 2022, 11,

119. https://doi.org/10.3390/

ijgi11020119

Academic Editors: Milan Konecny,

Jie Shen, Zhenlong Li and

Wolfgang Kainz

Received: 19 November 2021

Accepted: 30 January 2022

Published: 8 February 2022

Publisher's Note: MDPI stays neutra with regard to jurisdictional claims in published maps and institutional affiliations.

Copyright: (C) 2022 by the authors. Licensee MDPI, Basel, Switzerland. This article is an open access article distributed under the terms and conditions of the Creative Commons Attribution (CC BY) license (https:// creativecommons.org/licenses/by/ $4.0 /$ )
1 National Institute of Natural Hazards, Ministry of Emergency Management of China, Beijing 100085, China; 2102190073@cugb.edu.cn (Y.C.); chongxu@ninhm.ac.cn (C.X.); 2001200053@cugb.edu.cn (Y.H.)

2 School of Engineering and Technology, China University of Geosciences (Beijing), Beijing 100083, China; luozhihua@cugb.edu.cn

3 Key Laboratory of Compound and Chained Natural Hazards Dynamics, Ministry of Emergency Management of China, Beijing 100085, China

4 Key Laboratory of Landslide Risk Early-Warning and Control, Ministry of Emergency Management of China, Chengdu 610059, China

5 Institute of Geology, China Earthquake Administration, Beijing 100029, China; zhangpengfei@ies.ac.cn

6107 Geological Team, Chongqing Bureau of Geology and Minerals Exploration, Chongqing 401120, China; kcyzt@126.com

* Correspondence: xianglihe@ninhm.ac.cn

\begin{abstract}
At about 20:40 on 23 July 2019, a high-level and long-runout landslide occurred in Jichang Town, Shuicheng County, Guizhou Province (hereafter called the Shuicheng landslide). This slope failure was highly devastating, and most of the local residents were severely affected, including 52 dead or missing. Based on the information provided by field investigations, drilling boreholes, and Google Earth, we describe the landform and stratigraphy characteristics of the Shuicheng landslide in this study. Additionally, the dataset of 1158 ancient landslides near the Shuicheng landslide is obtained by Google Earth and ArcGIS, including their morphological scales and spatial distribution characteristics, to analyze the landslide development preference in this region. Furthermore, the causes of the Shuicheng landslide are discussed by analyzing the effects of active tectonic activities on the broken basalt and the steep terrain, as well as the trigger action of continuous heavy rainfall. Finally, a previous empirical prediction formula of sliding distance is verified by the Shuicheng landslide parameters and is applied into the width range calculation of the ancient landslide risk zones, which is a kind of risk source for future landslides. The result indicates the area up to $\approx 3500 \mathrm{~m}$ away from the landslide risk source should be concerned during engineering construction in the study area. This study provides significant scientific guidance for the risk management of potential landslide hazards in this area.
\end{abstract}

Keywords: Shuicheng landslide; landform; stratum; cause; risk zone

\section{Introduction}

As one of the most frequently occurred geological hazards [1], large landslides are often catastrophic with a broad influencing zone. Such landslides occur widely in China, posing severe threat to people's lives and property every year [2-5]. Although great efforts have been made in landslide investigations in China [6-9], a large number of landslides are still not accurately identified, monitored, and forecast, resulting in huge losses. One of the reasons for this situation is the lack of comprehensive understanding of the development characteristics and stability conditions of landslides. Among all landslides, high-level and long-runout landslides are generally difficult to be identified and monitored due to their high slide source elevation. Moreover, these landslides are characterized by substantial gravitational potential energy at the beginning, which can be converted into kinetic energy 
in a short time, thus usually leaving insufficient time for people evacuation in the dangerous places [10-12]. These kinds of landslides are often accompanied by impact and scraping effects, which lead to great damage to the landslide path and constantly destroy and carry away soil along the way. Although this process slightly decreases the movement speed of the landslide, its volume continues to expand, which results in larger distance of the landslide movement. Meanwhile, the influence and damage to the surrounding environment become greater as well $[13,14]$. Such a landslide hazard often results in heavy casualties and property losses. For example, a landslide at Sanxi Village, Dujiangyan, Sichuan Province in 2013 caused 44 people dead and 117 missing [15]. In the same year, more than 60 houses were destroyed and 46 people were killed during the Zhaojiagou landslide in Zhenxiong, Yunnan [16]. In 2015, a total of 37 people were claimed to be killed by a landslide at Lidong Village, Yaxi Town, Liandu District, Lishui City, Zhejiang Province [17]. Therefore, the study on the development characteristics and causes of such high-level and long-runout landslides is of great significance for disaster prevention and mitigation.

A large landslide occurred at Jichang Town, Shuicheng County, Guizhou Province (hereinafter called "the Shuicheng Landslide") at about 20:40 on 23 July in 2019 [10,18-20]. During this event, 21 houses were destroyed and nearly 1600 people were affected, including 43 dead and nine missing, with direct economic loss reaching 190 million yuan [10,21]. Previous studies show that the Shuicheng landslide is characterized by shearing out from a high position, high speed, and long movement distance, which is indicative of a typical single high-level and long-runout landslide [11]. Rong et al. (2020) suggested a way to predict landslides by the combination of the GeoDetector and Bayesian network model based on the Shuicheng landslide [1]. Gao et al. (2020) show the movement process of the Shuicheng landslide based on the numerical simulation [13]. Fan et al. (2020) and Ma et al. (2020) highlighted the impact of rainfall on the occurrence of the Shuicheng landslide [11,19]. There are numerous factors affecting a single landslide, such as rainfall [22-24], human engineering $[25,26]$, earthquakes $[5,27,28]$, etc. The above factors are the external causes of landslides. The internal factors include terrain or geomorphology [28-30], lithology and structure [27,28,31], etc. Wang et al. (2019) analyzed the influencing factors of geological disasters in southeastern Tibet and found that the occurrence of landslides is largely affected by internal factors [32]. In addition, the studies in Darjeeling-Sikkim Himalaya by Roy et al. (2015) [33] and in the alpine areas of Northern Norway by Louise et al. (2020) also showed the importance of internal factors in the development of landslides [34]. Consequently, the development characteristics of ancient landslides and new landslides in the same region always exhibit high similarities. Therefore, the establishment of the big data about regional ancient landslides is favorable to analyze the influencing factor of landslide development and propose scientifically the landslide risk management measure in this area. However, the investigations that comparatively analyze the influencing factors of both ancient and recently occurred landslides are rare.

In this paper, through a detailed field survey, drilling borehole, and geomorphic parameter extraction from Google Earth, we attempt to conduct a further analysis of the Shuicheng landslide and mainly focus on its geomorphological features and formation structure. Furthermore, the factors affecting the development of the landslides are analyzed by combining with the study of ancient landslides in this region, based on 3D analyst tool and spatial analyst tools in ArcGIS. Finally, the internal and external causes of the landslide are considered comprehensively, and the width of the landslide risk zone is given based on the ancient and modern landslide parameters and previous formulas. This case study provides a reference for recognizing similar high-level and long-runout landslides, and it would be beneficial for disaster prevention and mitigation, that is landslide risk management, and engineering construction in this region. 


\section{Geological Setting}

The Shuicheng landslide occurred in Pingdi Village, Jichang Town, Shuicheng County, Liupanshui City, western Guizhou Province ( $104^{\circ} 40^{\prime} 03.09^{\prime \prime}$ E, $\left.26^{\circ} 15^{\prime} 27.40^{\prime \prime} \mathrm{N}\right)$. There are a few traffic roads in the vicinity of the landslide area and only the 244 county road traverses through the middle and back of the slope body. Nearby, a retaining wall was built to widen the 244 county road, reducing local stability. However, the overall safety stability coefficient still meets the requirements of the code [6]. The average elevation of this area is higher than that of the rest of Guizhou province. The mountain range where the landslide occurred strikes in southwest to northeast, with several small gullies. No large surface rivers pass through the landslide area, except for the Beipanjiang river that flows through the north of the area. In addition, a reservoir that is manually excavated [10] is present at the front of the landslide area.

Shuicheng County is situated at the junction between the southeast margin of the Tibetan Plateau and the South China block (Figure 1a). It is also located on the southwest of the Panjiang syncline. Pleistocene fault structures develop well in the study area. Local geological features include the Yadu fault in the north, the Xiongwu fault, Xiaganhe fault and Youjiang fault in the south, and the Tianshenqiao fault and Xiaojiang fault in the west (Figure 1b), with folds and faults interlaced, leading to strong rock fragmentation. Many earthquakes have occurred around the Shuicheng landslide, especially along the Xiaojiang fault in history (Figure 1b). For example, the $2020 \mathrm{Mw5}$.1 Qiaojia earthquake and the 2014 Mw6.2 Ludian earthquake occurred in the northwest of the Shuicheng landslide area.

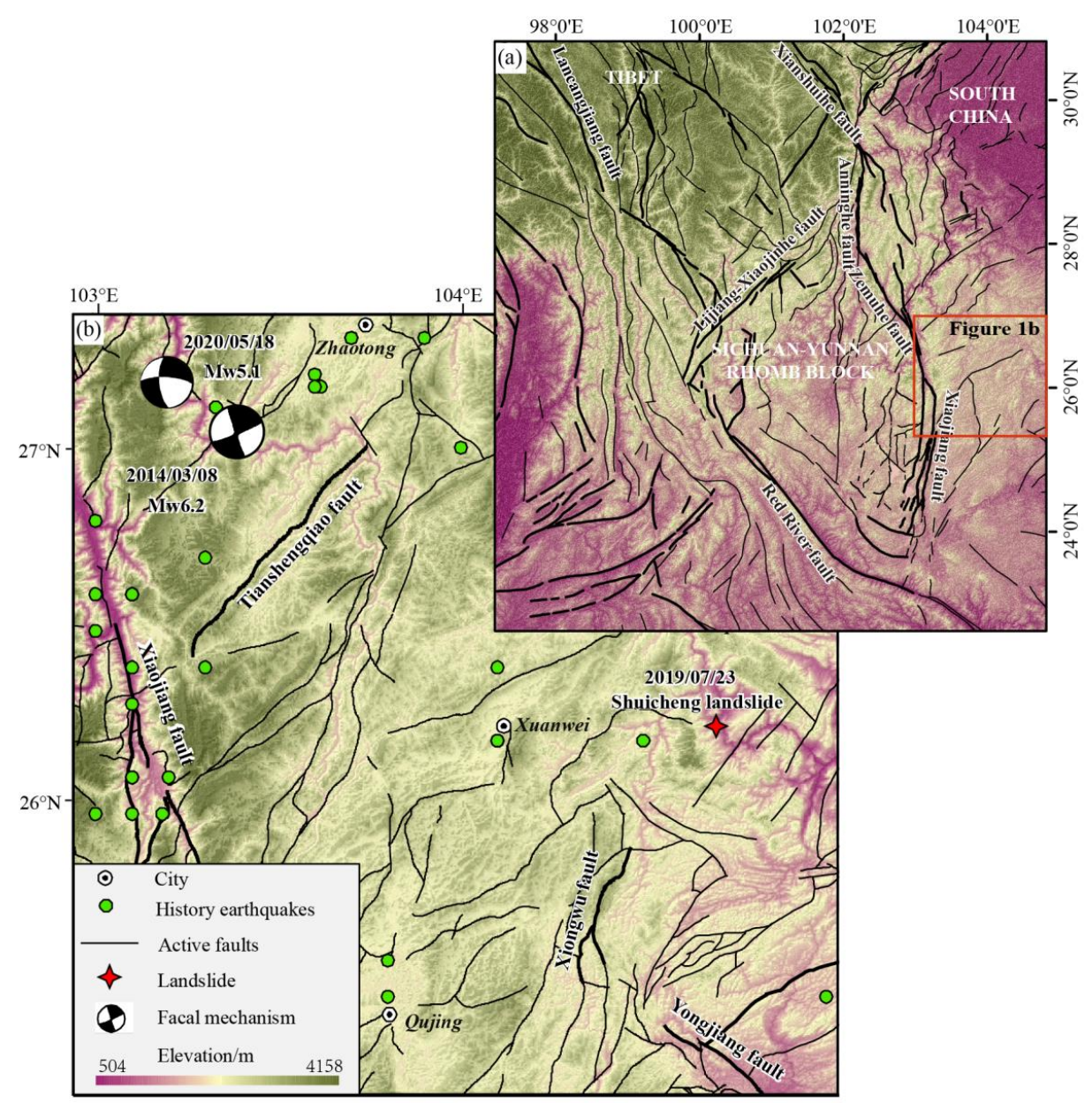

Figure 1. Tectonic setting in the Shuicheng landslide area. (a) Simplified tectonic map of the southeast Tibetan plateau and adjacent regions. The red box is the range of (b). (b) Detailed tectonic setting and historical earthquakes around the Shuicheng landslide. 
Different from most of the landslides in Guizhou Province, the Shuicheng landslide occurred in basalt strata rather than an upper-hard and lower-soft stratum or an interbedded stratum with soft and hard layers [10]. The strata nearby (Figure 2) are mainly Permian sand shale intercalated with coal, chert limestone, basalt $\left(\mathrm{P}_{2}\right)$ and limestone intercalated with dolomite and sand shale $\left(\mathrm{P}_{1}\right)$, and their combination $(\mathrm{P})$ in the middle; Triassic limestone and sand shale $\left(\mathrm{T}_{1}\right)$, dolomite, limestone interbedded shale $\left(\mathrm{T}_{2}\right)$, and their combination $\left(\mathrm{T}_{1+2}\right)$, and Triassic lithic quartz sandstone and sandy clay interbedded coal $\left(\mathrm{T}_{3}\right)$; Carboniferous limestone intercalated with shale and sand shale intercalated with coal or aluminite $\left(\mathrm{C}_{1}\right)$, limestone and dolomite $\left(\mathrm{C}_{2}\right)$, and their parallel beds $(\mathrm{C})$. In addition, there is also a small amount of Jurassic sand shale intercalated with limestone $\left(\mathrm{J}_{1}\right)$; the Tertiary maroon-red conglomerate and coal-intercalation line of the pebbly sand and mudstone (E); Devonian quartz sandstone intercalated with sandy shale $\left(\mathrm{D}_{1-2}\right)$; Cambrian dolomite, limestone and calcareous limestone $\left(\varepsilon_{3}\right)$.

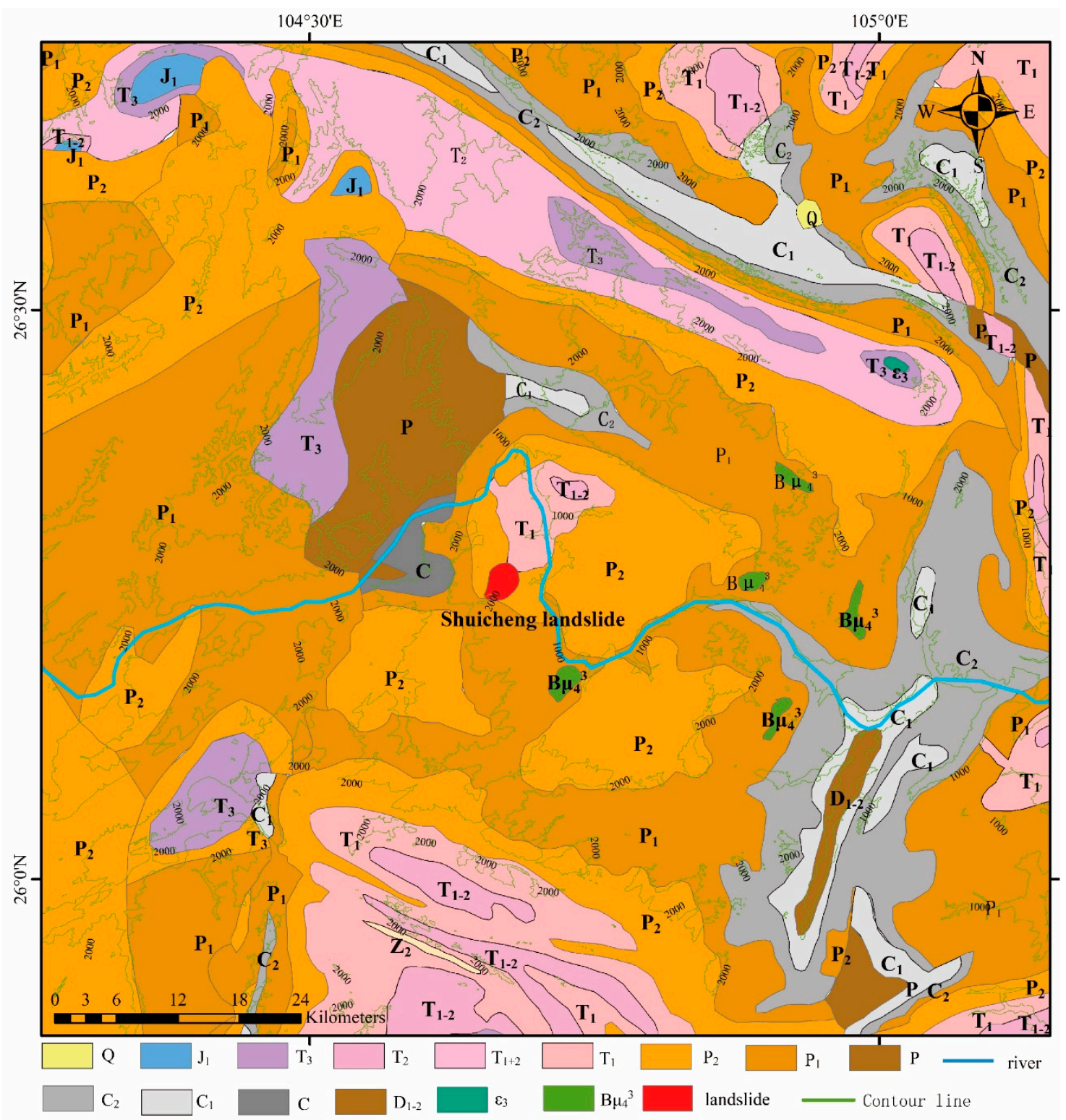

Figure 2. Geological map around the Shuicheng landslide. Q: Quaternary; $\mathrm{J}_{1}$ : Early Jurassic; $\mathrm{T}_{3}$ : Late Triassic; $\mathrm{T}_{2}$ : Middle Triassic; $\mathrm{T}_{1+2}$ : Early-Middle Triassic; $\mathrm{T}_{1}$ : Early Triassic; $\mathrm{P}_{2}$ : Late Permian; $\mathrm{P}_{1}$ : Early Permian; P: Early-middle Permian; $\mathrm{C}_{2}$ : Middle Carboniferous; $\mathrm{C}_{1}$ : Early Carboniferous; C: Early-middle Carboniferous; $\mathrm{D}_{1-2}$ : Early-middle Devonian; $\varepsilon_{3}$ : Cambrian Epoch3; $\mathrm{B}^{3}{ }_{4}$ : Variscan. 


\section{Materials and Methods}

In this study, the geomorphological and stratigraphic characteristics of the Shuicheng landslide are obtained by field investigations and borehole sampling. In the field survey, we record the outcrops of the landslide rear wall and the scraping traces left in the sliding zone through direct observations and then determine their lithology accordingly. Combined with the measurements in situ and pictures from Unmanned Aerial Vehicles (UAV), the overall sliding direction of the landslide is estimated, and the topographical and geomorphological features are recognized in detail [7,9]. In addition, on-site drilling and sampling work are also carried out. A total of 11 boreholes are arranged in the sampling work, among which boreholes 2,4 , and 5 are perpendicular to the sliding direction of the landslide, and boreholes 1, 2, 3, 6, 7, 8, 9, 10, and 11 are parallel to the sliding direction of the landslide. Based on the stratigraphic information and borehole data of the slope area before and after the landslide occurrence, we plot the landslide cross-section. The material composition of the sliding body, sliding surface, and sliding beds of the landslide is obtained by drilling, and the influence of strata and structural factors on the landslide is subsequently discussed based on data of lithology, weathering degree, and geological structure. Additionally, through Google Earth, we can obtain remote sensing images to observe the Shuicheng landslide and recognize ancient landslides. As a result, the elevation, slope angle, area, and run-out distance of the Shuicheng landslide are obtained, which are subsequently used to verify the empirical prediction formula of the sliding distance of the landslide.

Different from most of the previous studies, we investigate the ancient landslides around the Shuicheng landslide. Due to human activities, the characteristics of such old slope failures are not remarkable and thus are difficult to be identified through field investigations. To solve this problem, remote sensing technology and Google Earth Platform are selected to identify ancient landslides and build an inventory in the study area $[19,35,36]$. The interpretation signs include direct and indirect ones. The direct signs are the images with obvious boundaries, including the landslide perimeter, landslide steps, dislocation and tension fractures at the back edge of the landslide, and the deposited body at the front of the landslide. The indirect interpretation signs are topographic changes induced by the landslide, such as the uncommon flat topography near steep gullies and the channel shifts to the side away from the landslide. According to its shape, the landslide body is described into multiple polygons. The polygons from Google Earth are imported into ArcGIS. Combining the digital elevation model (DEM) data, the topographic and geometric parameters and spatial distribution characteristics of ancient landslides are analyzed by a 3D analyst tool and spatial analyst tools in ArcGIS [37-40]. The spatial distributions of the ancient landslides in the geomorphic factors (elevation, slope, and aspect) in this region are characterized by landslide number density (LND) and landslide area percentage (LAP). In this study, the geomorphic factors are extracted from DEM with a $12.5 \mathrm{~m}$ resolution from the Advanced Land Observation Satellite (ALOS). Stratum data are extracted from the 1:1,500,000 geological map of Guizhou province (China Geological Atlas).

Finally, combining rainfall and geographical data and the information from previous studies, the internal and external causes of the Shuicheng landslide are discussed. Based on the geomorphic parameters of the Shuicheng landslide and other ancient landslides, the previous formula of Corominas (1996) is applied to determine the width range of risk zone of future potential landslides in the study area [41].

\section{Results}

\subsection{Characteristics of the Shuicheng Landside}

\subsubsection{Landform Features}

Prior to the landslide occurrence, the landslide area was a structurally eroded midmountain landform, where the terrain is high in the south and west and low in the north and east. The slope angle ranges from $15^{\circ}$ to $25^{\circ}$, with gentle front edges of approximately $3^{\circ}$ (Figure 3). A large number of residential buildings are distributed in the front of the landslide area, and the middle and back edges are densely covered with vegetation. 
Scattered residential buildings are distributed in the middle of the landslide area, and the 244 county road traverses through the back edge of the landslide area (Figure $4 \mathrm{a}$ ).

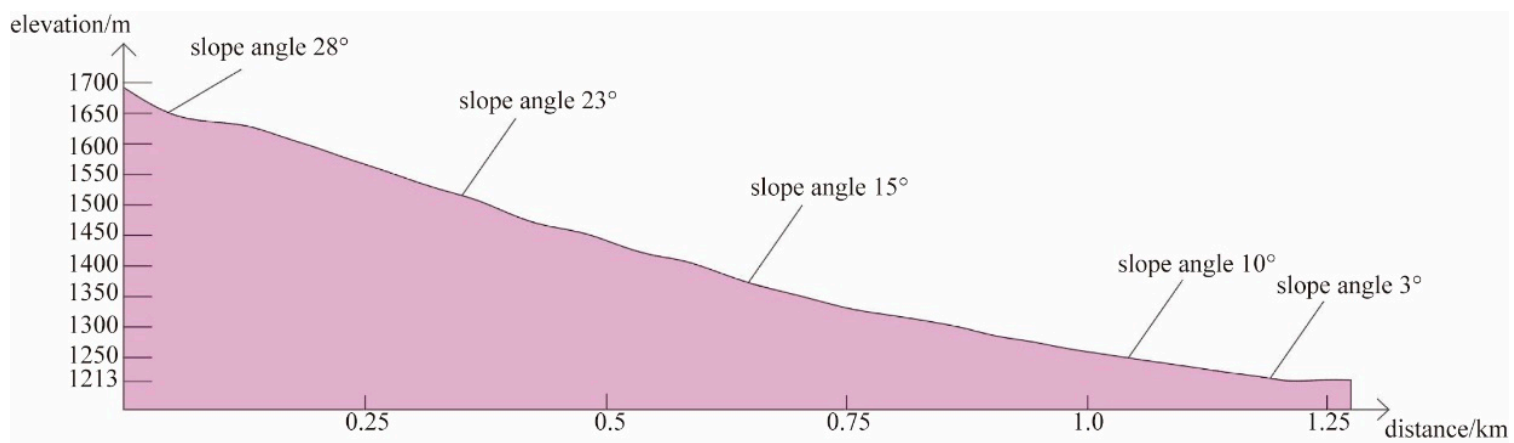

Figure 3. Cross-section of the slope before the landslide obtained by Google Earth (location is shown in Figure 4b).

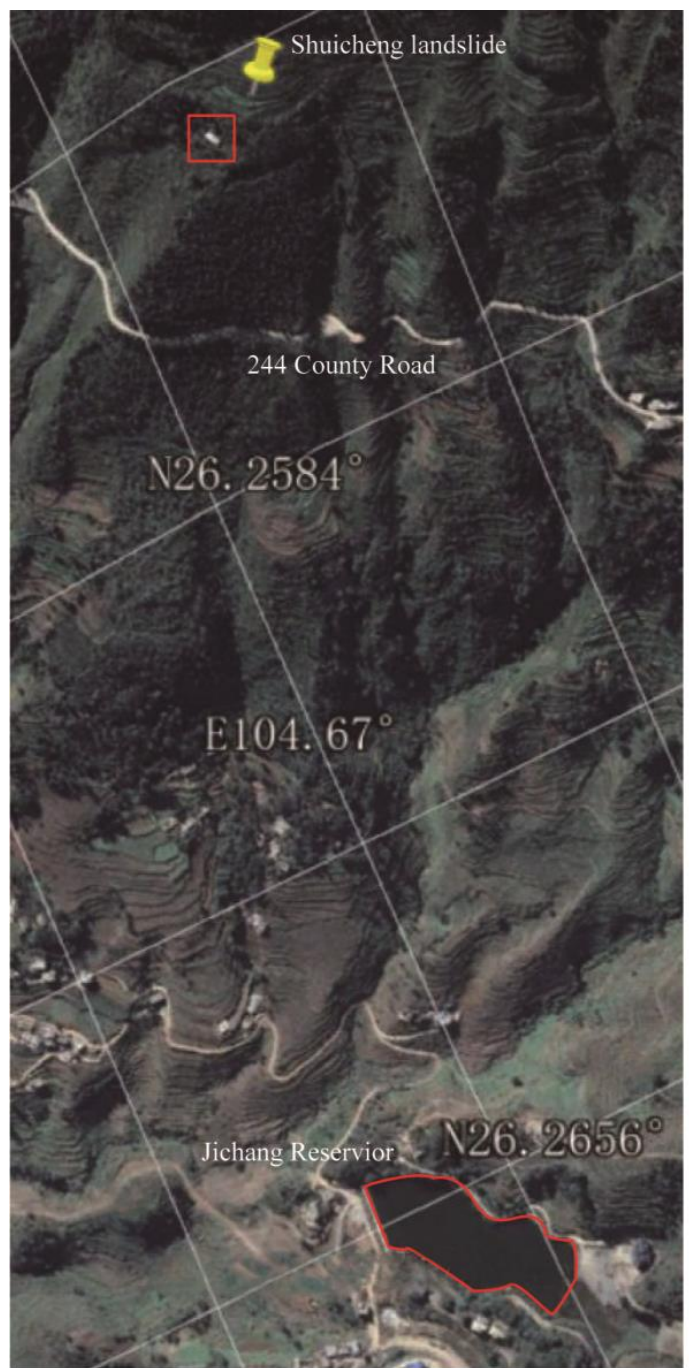

(a)

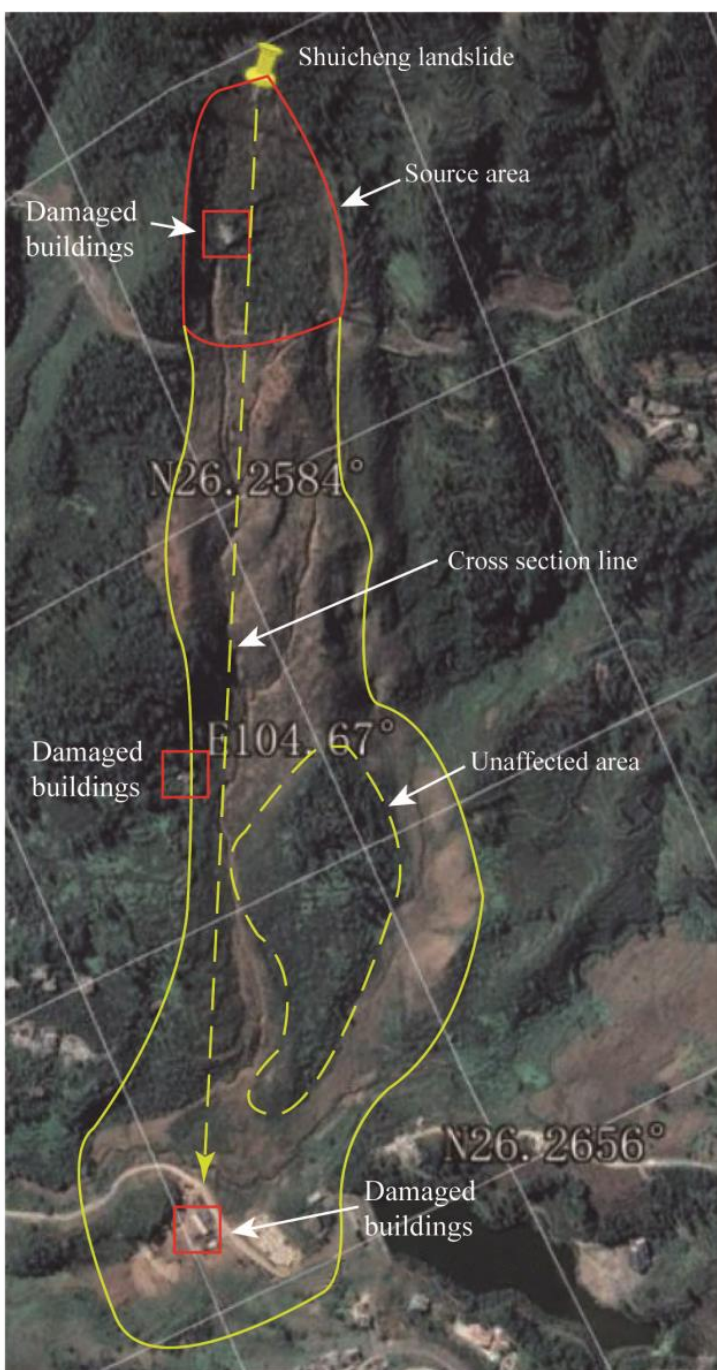

(b)

Figure 4. Comparison of pre-sliding satellite image from Google Earth in 2018 (a) and post-sliding satellite image from Google Earth in 2020 (b). The landslide area is circled in a yellow solid line. Red boxes mark residential buildings. 
The results of field investigations show that the whole vegetation has been swept away by the impact and scraping of the landslide body. At the front of the landslide area, some residential buildings are buried by the landslide material, and the terrain becomes relatively gentle, with a relief of $20.10 \mathrm{~m}$ and a small slope variation (Figure 5a). The residential buildings and vegetation in the central landslide area are almost unaffected due to the protection of the exposed rigid geological body (Figure 5b). The landslide body itself is broken after collision with the rigid geological body, and resumes its downward movement along the two gullies. The measurement results on Google Earth show two gully trends respectively in $\mathrm{N}^{\circ} \mathrm{E}$ and $\mathrm{N} 34^{\circ} \mathrm{E}$. There are plentiful traces of impact and scraping movement at the site [13]. At the back edge of the landslide area, the 244 County Road is destroyed and buried by some landslide material, and the exposed basalt wall is visible on the back wall (Figure 5c).

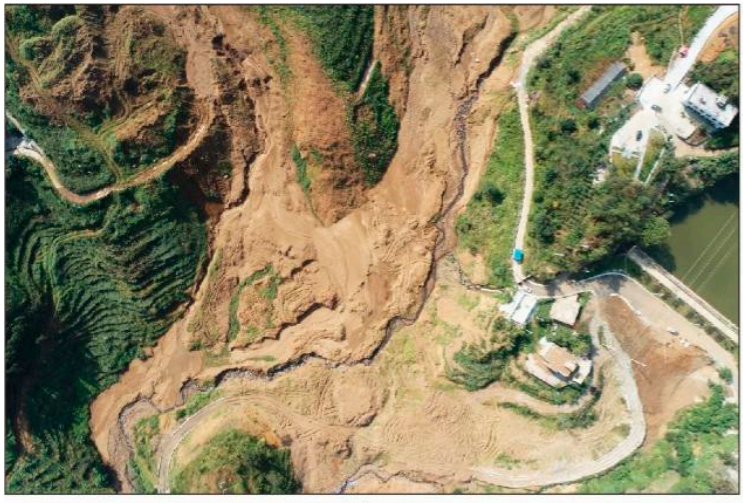

(a)

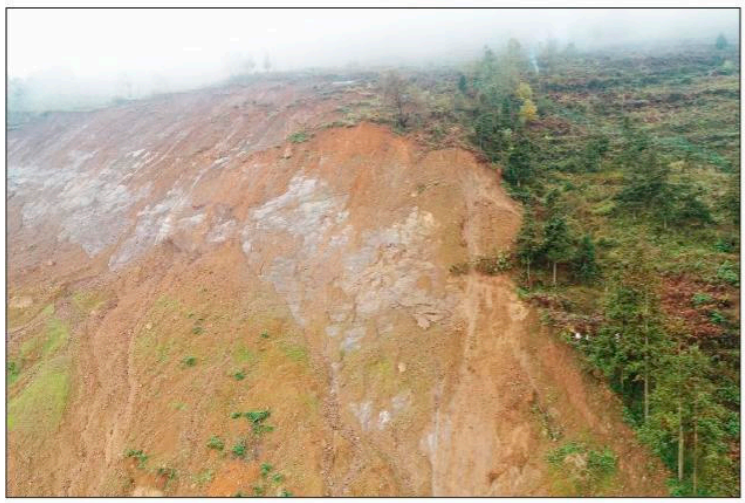

(c)

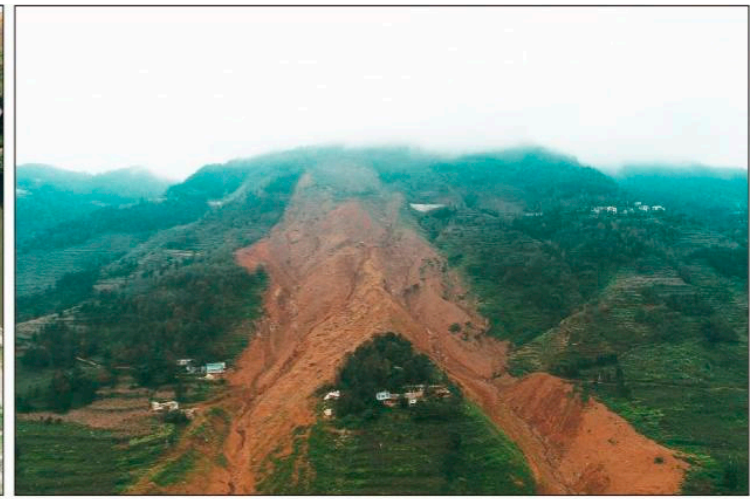

(b)

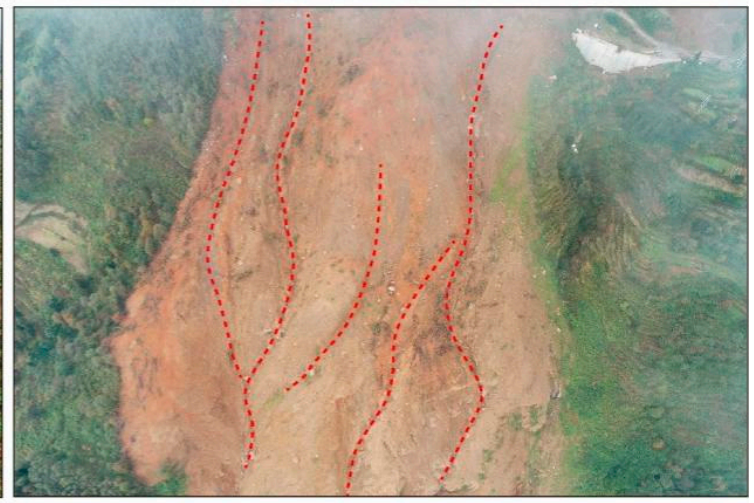

(d)

Figure 5. Field photos of the Shuicheng landslide: (a) landslide accumulation areas in Shuicheng. (b) Subsequent landslide movement along the gullies after impacting the hard body. (c) Photos of the back wall of the source area. (d) Scratches in the shoveling and scraping area (dotted lines denote scraping marks).

From the images obtained by Google Earth, it can be seen that a residential building in the landslide source area is destroyed and transferred down some distance by the landslide (red panel in Figure 4b). The parameters from Google Earth show that the landslide body is sheared out at an elevation of about $1690 \mathrm{~m}$ and stopped and piled up at an elevation of $1210 \mathrm{~m}$. Namely, the relative elevation difference between the front and back edges is $480 \mathrm{~m}$, and the runout distance is measured as $1300 \mathrm{~m}$. In addition, most previous studies divided the Shuicheng landslide into three parts: the source area, the shoveling and scarping area, and the accumulation area $[6,10,13]$, the first of which is the part from the rear edge of the landslide to the 244 county road. Our calculation suggests that the total area of the Shuicheng landslide is about $348,600 \mathrm{~m}^{2}$, and the area of the source area is about $33,200 \mathrm{~m}^{2}$. 


\subsubsection{Stratigraphic Structure}

The landslide deposits include Holocene colluvial $\left(\mathrm{Q}_{4}{ }^{\mathrm{del}}\right)$ silty clay and block rock, with underlying bedrock (basalt) of the second member $\left(\mathrm{P}_{2} \beta^{2}\right)$ of the Upper Permian Emeishan Basalt Formation (Figure 6). According to drilling borehole data, each geotechnical layer is described as follows (from top to bottom):

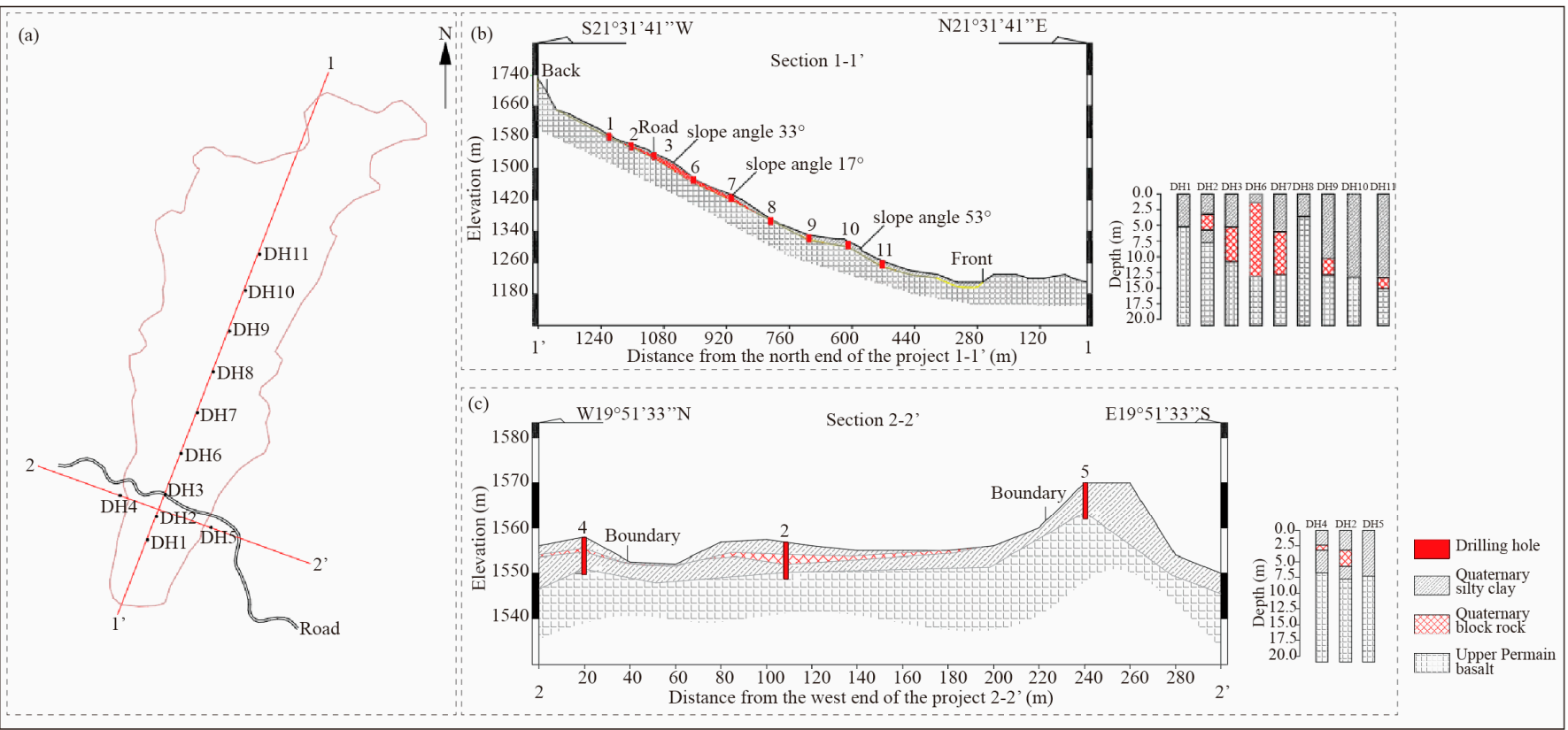

Figure 6. Geological cross-section of the Shuicheng landslide revealed by boreholes. (a) Location of boreholes; (b) Section along 1-1' (sliding direction of the landslide, see (a) for the position of the section); (c) Section along the 2-2' section (perpendicular to the sliding direction of the landslide; see (a) for the position of the section); DH: drilling hole.

(1) Quaternary landslide deposits $\left(\mathrm{Q}_{4}{ }^{\mathrm{del}}\right)$

Block rock: yellowish brown, slightly wet and slightly dense, composed of basalt blocks, gravel and silty clay, with particle sizes of 22-350 $\mathrm{mm}$ and a proportion of about $55-60 \%$. Silty clay is plastic and fills the rock. The thickness of the block rock revealed by the borehole is 2.69 (DH2)-12.6 m (DH6).

Silty clay (basalt soil): reddish brown, slightly wet, low strength, low toughness, smooth knife-cutting surface. The thickness exposed by borehole is 0.25 (DH4)-14.27 m (DH11).

(2) The second member $\left(\mathrm{P}_{2} \beta^{2}\right)$ of the Emeishan Basalt Formation in upper Permian

Basalt: gray, porphyritic, and massive in structure. The porphyritic crystals are mainly granular pyroxene with a size range from 1 to $3 \mathrm{~mm}$, and the matrix is mainly plagioclase microcrystalline and vitreous with a glassy interlaced structure. The rock mass is short columnar or columnar, which is the main underlying bedrock of the landslide area. After the landslide occurred, exposed basalt strata have become clearly visible at the back edge of the landslide area, exhibiting obvious scratches on the exposed surface (Figure $5 \mathrm{~d}$ ).

The landslide cross-section (Figure 6b) shows that the deposited body presents a trend of steady thickening along the movement direction of the landslide, whereas its minimum thickness appears at borehole 8 . The rigid geological body in front of borehole 8 has broken the high-speed declining landslide into small particles along the low-lying gullies. As a result, the thickness of the unconsolidated sediments at borehole 8 has become smaller. The cross-section vertical to the landslide movement direction (Figure 6c) indicates that the thickness and composition of the deposits are basically similar in boreholes 2,4 , and 5, illustrating that the uniform-thickness 
deposits on the original slope belong to an ancient landslide. In contrast to the deposits in two undamaged walls of the landslide (boreholes 4 and 5), the proportion of block rock in deposits is larger, and the surface of bedrock (basalt) within the landslide (borehole 2) is low lying, suggesting that the basalt layer was damaged when the Shuicheng landslide occurred.

\subsection{Lessons Learned from Ancient Landslides}

In this study, we analyze 1158 ancient landslides in the range of $26-26.71^{\circ} \mathrm{N}$ and $104.27-105^{\circ} \mathrm{E}$, with a total distribution area of about $5685 \mathrm{~km}^{2}$ and a total occupying area of approximately $177.63 \mathrm{~km}^{2}$ (Figure 7a). According to the relationship between landslide volume and area $\left(\mathrm{V}=1.3147 \times \mathrm{A}^{1.2085}\right)$ [42] and size division method [43], 13 landslides (accounting for about $1.12 \%$ of the total) are determined to be small ones with a volume less than $10 \times 10^{4} \mathrm{~m}^{3}$. The volume of 437 landslides (about $37.74 \%$ of the total) ranges from $10 \times 10^{4}$ to $100 \times 10^{4} \mathrm{~m}^{3}$, belonging to medium-sized ones. There are 654 landslides (about $56.48 \%$ of the total) with a volume ranging from $100 \times 10^{4}$ to $1000 \times 10^{4} \mathrm{~m}^{3}$ as large ones. Of these, 53 landslides (about $4.58 \%$ of the total) with the volume ranging from $1000 \times 10^{4}$ to $10,000 \times 10^{4} \mathrm{~m}^{3}$ are attributed to extremely large slope failures. Only one landslide with a volume greater than $10,000 \times 10^{4} \mathrm{~m}^{3}$ is regarded as giant size. In general, the landslide hazards in this region are mostly characterized by medium and large-size ones (Figure 7c), with a limited number of small and extremely large scales. Additionally, the landslide number density (LND) and landslide area percentage (LAP) in the study area are $0.2037 \mathrm{~km}^{-2}$ and $3.12 \%$, respectively.

The lowest elevation of the study area is $624 \mathrm{~m}$, while the highest is $2826 \mathrm{~m}$, with an elevation difference about $2202 \mathrm{~m}$ (Figure 1). The terrain is highly fluctuated with many mountains. In the region, the elevation of the old landslide source area is relatively large, mostly over $1500 \mathrm{~m}$, accounting for about $80 \%$ of the total. The peaks of the number of ancient landslides appear in 1901-2100 m (Figure 7b). The slope feet are mostly distributed in $1501-1700 \mathrm{~m}$ (Figure $7 \mathrm{~b}$ ). Here, $80 \%$ of the ancient landslides are greater than $100 \mathrm{~m}$ in the elevation differences, most of which are 100-200 m (Figure 7b).

For elevation factors, the peak values of LAP and LND are $6.9 \%$ and $0.31 \mathrm{~km}^{-2}$, respectively, in the elevation range of $900-1300 \mathrm{~m}$. This is because the area of the region with elevation of $900-1300 \mathrm{~m}$ and above $2500 \mathrm{~m}$ is smaller, while that corresponding to $1700-2100 \mathrm{~m}$ is larger. The landslide number density values in the region with elevations $<900 \mathrm{~m}, 1300 \mathrm{~m}-1700 \mathrm{~m}, 1700 \mathrm{~m}-2100 \mathrm{~m}, 2100 \mathrm{~m}-2500 \mathrm{~m}$, and $>2500 \mathrm{~m}$ are $0.007 \mathrm{~km}^{-2}$, $0.22 \mathrm{~km}^{-2}, 0.14 \mathrm{~km}^{-2}, 0.01 \mathrm{~km}^{-2}$, and $0.28 \mathrm{~km}^{-2}$, respectively. The curve trend of LAP is basically consistent with that of LND (Figure $8 b$ ). With the increase in slope angle, LAP is positively correlated with slope angle, while LND increases initially and then decreases with the increase in slope angle. Among them, when the slope is greater than $50^{\circ}$, LAP increases while LND decreases, which may be caused by a single large landslide (Figure 8d), indicating that large landslides are possibly generated by high-angle slopes. The area corresponding to each type of the slope aspect in this region displays little change, ranging from 800 to $1000 \mathrm{~km}^{2}$. The LND value on the north-dipping slope is basically equal to that on the northwest-dipping slope. The value reaches $0.3 \mathrm{~km}^{2}$, which is the peak value of LND. Moreover, the LAP value of the slope that inclines to these two directions is also significantly greater than that of the LAP value in other directions (Figure 8f), which is followed by the slope inclining to the $\mathrm{W}$ and NE directions. This phenomenon demonstrates that the north-facing slope is a landslide-prone zone compared with the south-facing slope. 


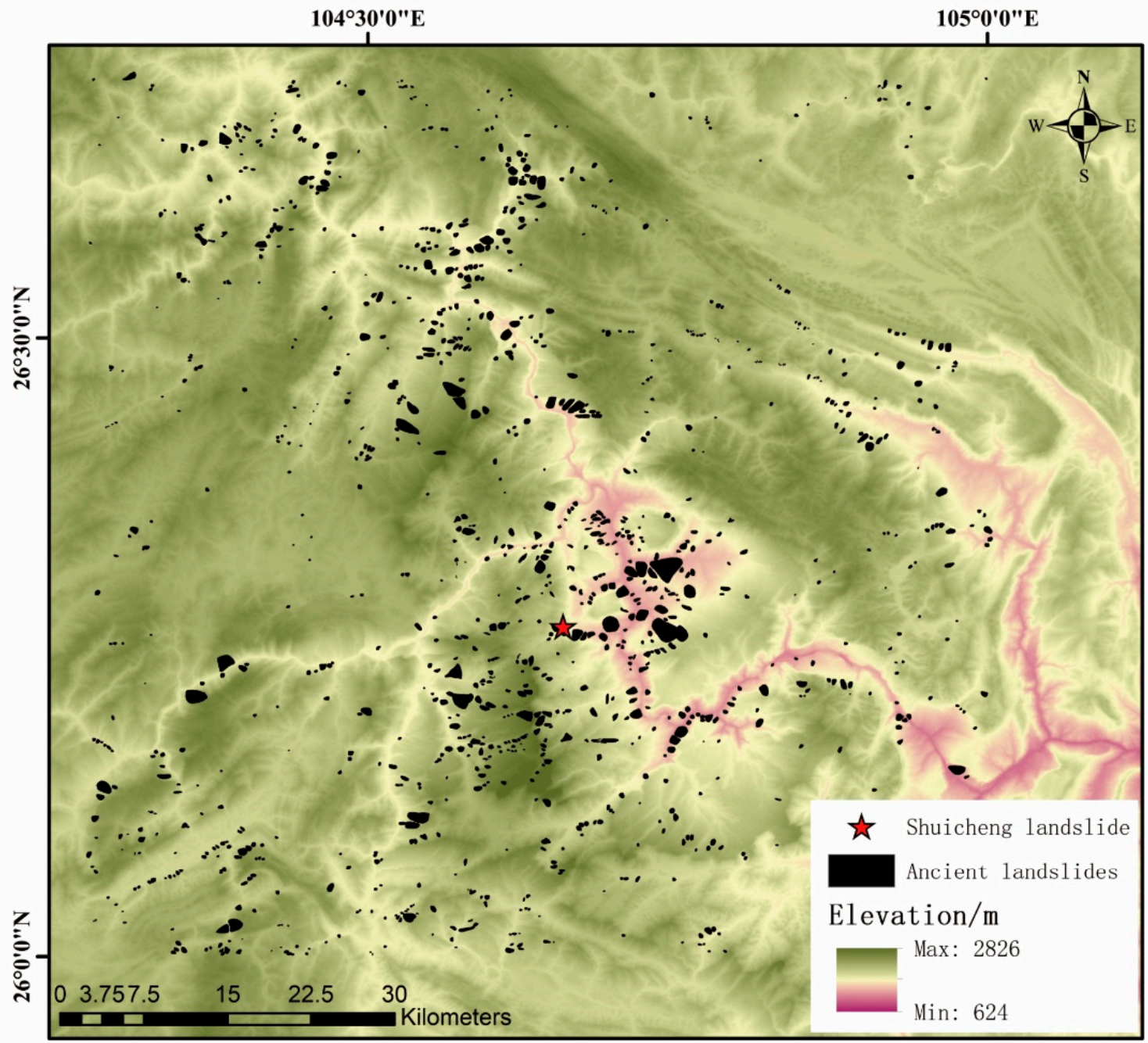

Elevation differences (m)

(a)

$\begin{array}{lllllll}0 \sim 100 & 100 \sim 200 & 200 \sim 300 & 300 \sim 400 & 400 \sim 500 & 500 \sim 600 & >600\end{array}$

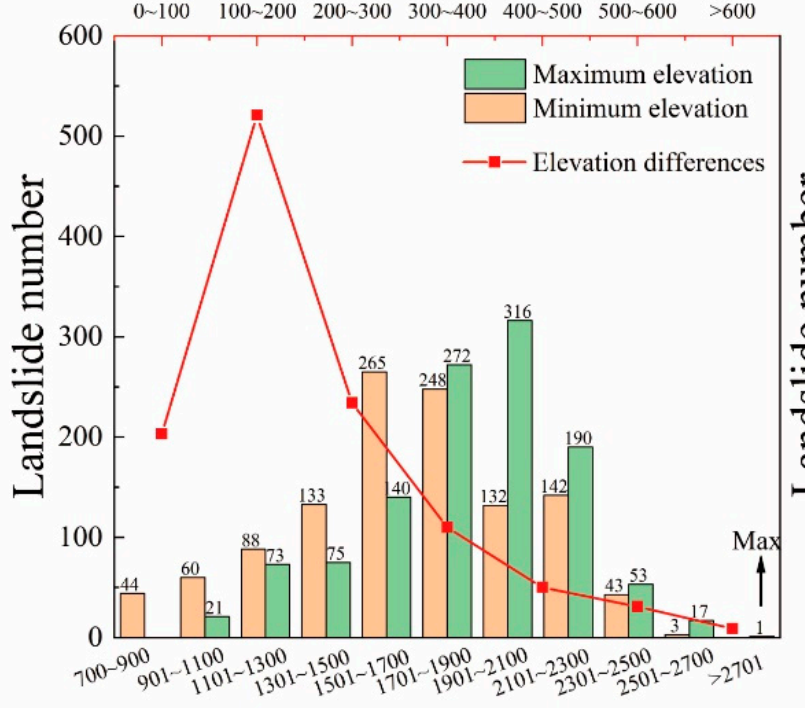

Elevation (m)

(b)

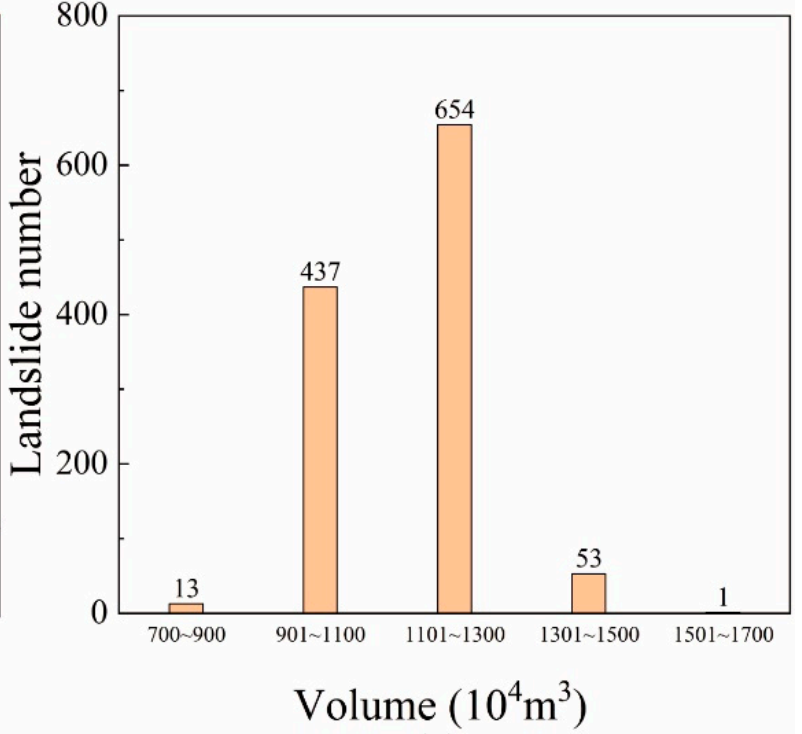

(c)

Figure 7. (a) Shaded terrain map showing ancient landslides around the Shuicheng landslide. (b) Number of ancient landslides versus elevations of top (Maximum) and toe (Minimum) of slope and elevation differences. (c) Number of ancient landslides versus their volumes. 


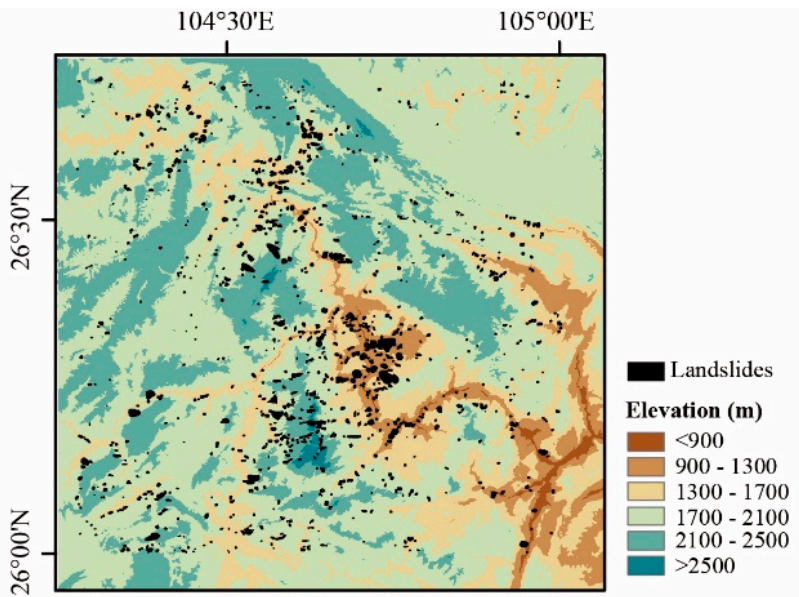

(a)

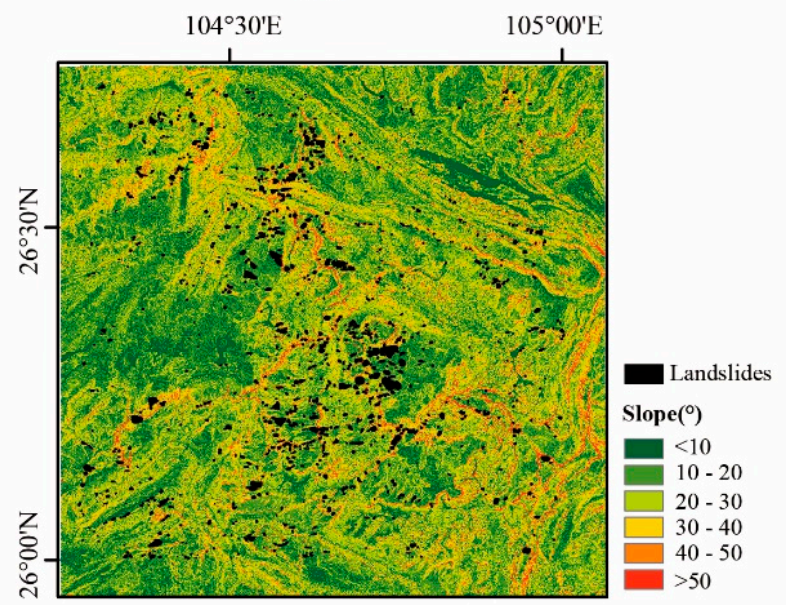

(c)

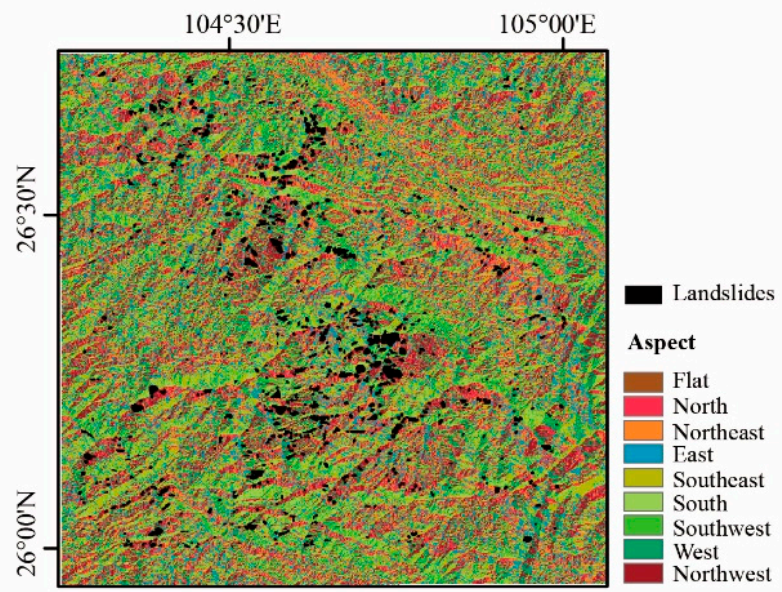

(e)

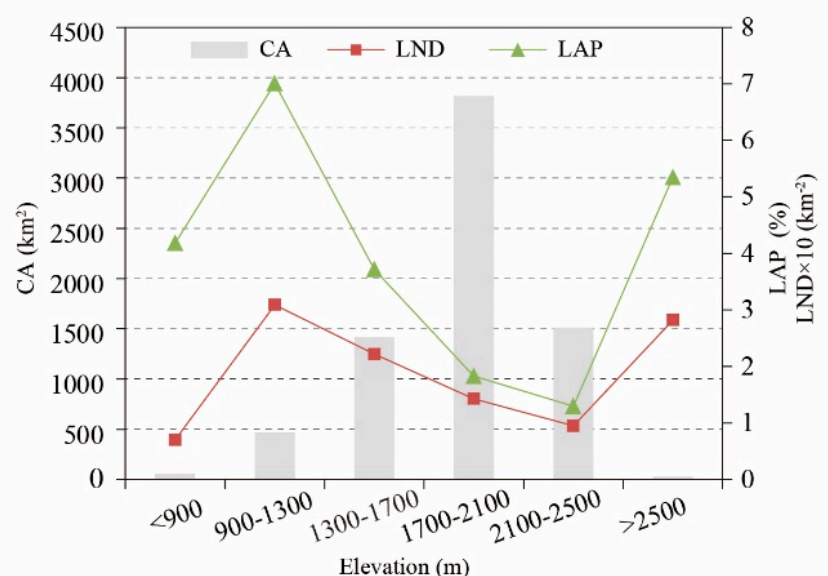

(b)

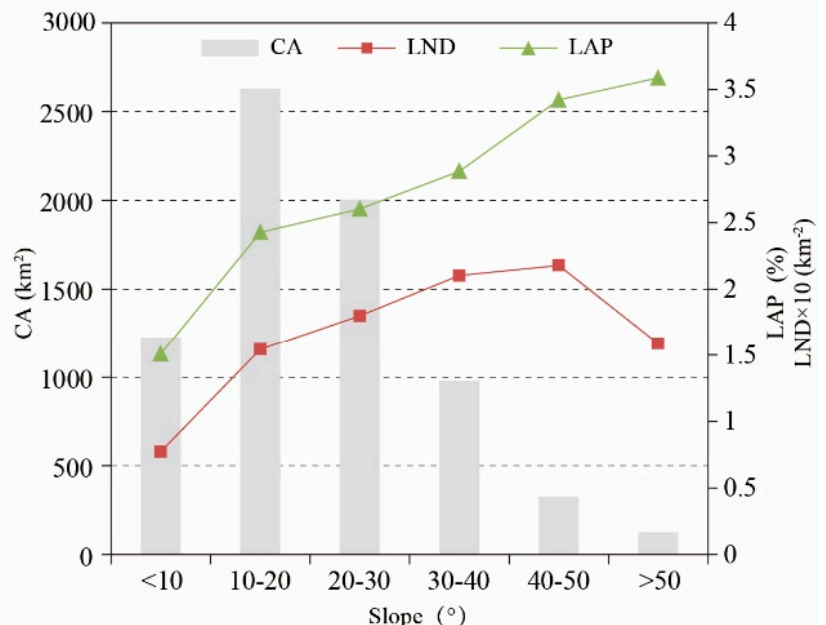

(d)

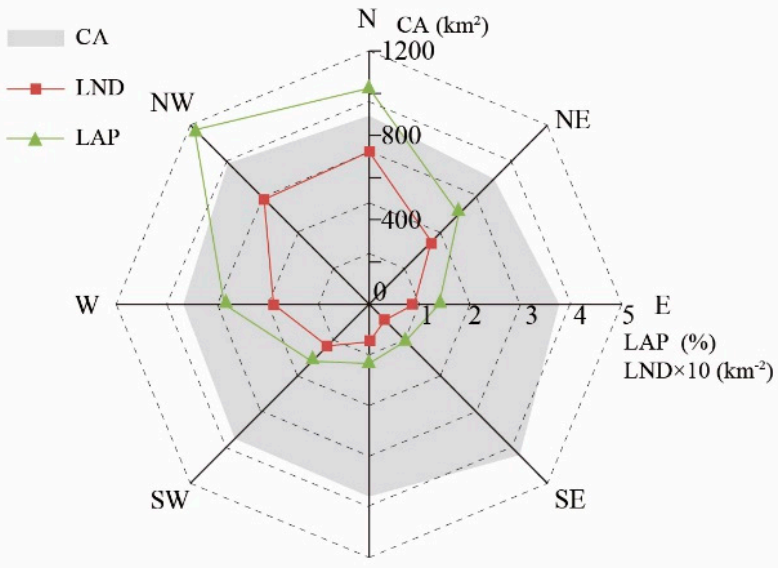

s (f)

Figure 8. Distribution (left) and correlation (right) of landslides with different topographic factor classifications using landslide area percentage (LAP) and landslide number density (LND). $(\mathbf{a}, \mathbf{b})$ Elevation; (c,d) Slope angle; $(\mathbf{e}, \mathbf{f})$ Aspect. CA: classification area.

\section{Discussion}

\subsection{The Cause of the Shuicheng Landslide}

The Shuicheng landslide occurred in the Upper Permian Emeishan basalt formation, which hosts substantial columnar joints and structural fissures, presenting a cataclastic- 
mosaic structure. The vast majority of rock joints have a tendency of $\mathrm{N} 30^{\circ} \mathrm{E}$, which is in high accordance with the sliding direction $\mathrm{N} 23^{\circ} \mathrm{E}$ of the Shuicheng landslide [6]. This may be associated with strong tectonic activity from the action between the southeast Tibet plateau and south China, as reflected by frequent historical earthquakes (Figure 1a). In the study area, multiple structural deformation areas interact with each other, with welldeveloped folds and faults. The strong tectonic activity leads to well-developed basalt joints, especially those dipping in the north direction, in which the rocks are structurally unstable or even broken $[27,29]$. Thus, the north-facing slopes are prone to landslide in this area (Figure 8). Under long-term weathering, a clay layer has gradually formed on the surface of the joints, reducing the mechanical strength of the basalt. The strong tectonic activity is also a reason of the formation of abundant mountains or grand canyons, with large terrain fluctuations and topographic reliefs, resulting in frequently occurred landslides with high elevation differences (Figure 7). A landslide similar to this one that starts at a higher elevation can convert the gravitational potential energy into a huge amount of kinetic energy at a high speed once it is sheared out, thereby providing conditions for the occurrence of landslides [13].

According to the statistics shown in Figure 9, rainfall in Jichang Town begins to increase and rock mass starts to gradually collapse. Except for the $85 \mathrm{~mm}$ rainfall on July 23, the daily rainfall on June 19 and June 25 also respectively reaches $82 \mathrm{~mm}$ and $59 \mathrm{~mm}$, which belong to the level of heavy rain to rainstorm [20,44,45]. Therefore, it is speculated that the occurrence of the landslide is correlated with the accumulated rainfall of several days rather than the heavy rainfall on the same day. The reasons for the influence of accumulated rainfall on landslide stability are listed as follows:

(1) The original slope surface before the occurrence of landslide is mainly composed of clay after strong weathering of basalt. Clay has poor permeability and is not conducive to the discharge of groundwater. Furthermore, in order to widen the neighboring highway, the construction team has built a retaining wall in the front of the landslide body, blocking the natural drainage channel of downward groundwater. In addition, the wall further obstructs the discharge of groundwater, resulting in increasing the water content of the slope soil under the condition of several days of rainfall [19].

(2) Several days of rainfall have resulted in the rise of the hydrostatic pressure of groundwater, while the undischarged groundwater might have soaked soil for a long time. Under the condition of high hydrostatic pressure, the original structure of basalt rock masses is destroyed, and the individual joints and fissures are connected to form larger fissures. The cracks formed by the destruction are quickly filled with groundwater, which continue to destroy the rock structure and further weaken the strength of the soil until the landslide occurrence when the rock masses are sheared out from the high elevation, causing a huge disaster [46-48].

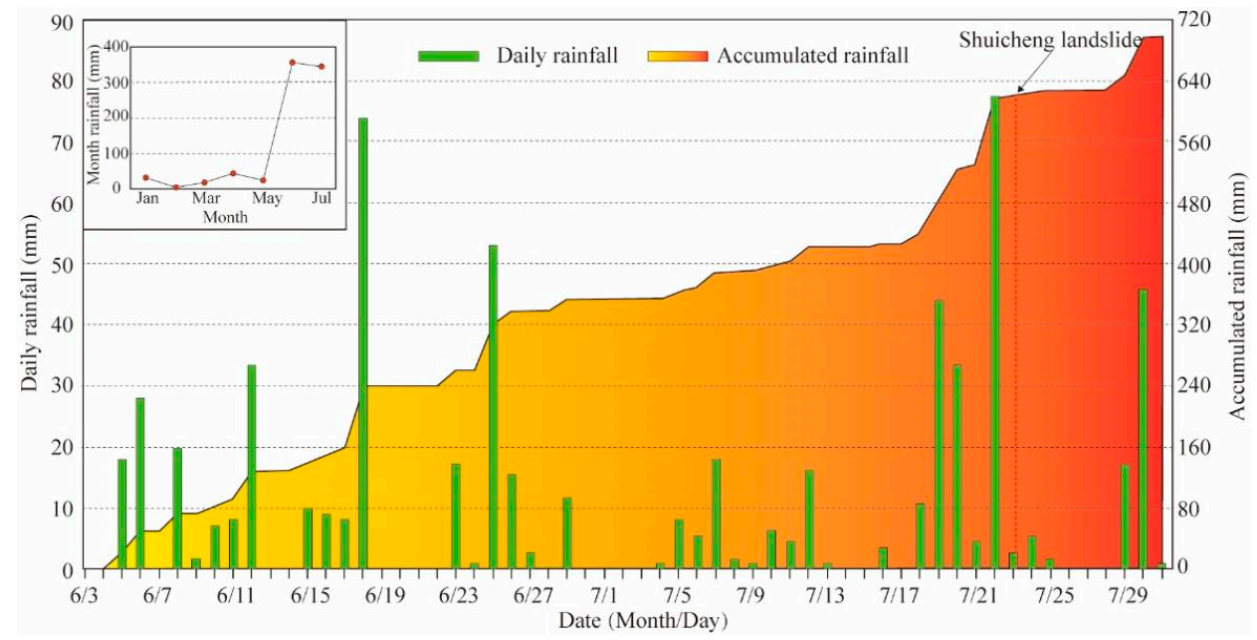

Figure 9. Rainfall statistics of Jichang Town before and after the occurrence of the Shuicheng landslide [11]. 
In addition, combined with remote sensing images and field investigations, Ma et al. (2020) proposed that the movement route of the landslide is consistent with the underground drainage path [19]. This result shows that the groundwater cannot be drained, and the water content of the soil along the drainage channel rises rapidly, leading to the instability of the surrounding soil and the subsequent destruction and movement of the landslide along the path. It also indicates that continual heavy rainfall and groundwater could not be discharged in time is the main factor to trigger landslides [19].

\subsection{Suggestions on the Risk Zone of Landslides}

Previous studies have confirmed that the sliding distance of a landslide can be obtained by the following empirical prediction formula [41]:

$$
\log \mathrm{L}=0.085 \log \mathrm{V}+\log \mathrm{H}+0.047+\varepsilon,
$$

where $\mathrm{L}$ is the sliding distance of a landslide (i.e., the horizontal distance between the backyard of the landslide area and the farthest end of the landslide). $\mathrm{V}$ is the landslide volume, $\mathrm{H}$ is the slope height, and $\varepsilon$ is the prediction error that obeys normal distribution $\mathrm{N}(0,0.016)$. The confidence coefficient is $95 \%$ as the value is \pm 0.235 . Combining the formula of the landslide volume $\left(\mathrm{V}=0.106 \times \mathrm{A}^{1.388}\right.$, where $\mathrm{A}$ is the area of source area of a landslide) [49], we can obtain the empirical sliding distance of the Shuicheng landslide (Ls). Based on the results from previous studies and Google Earth, the area of source area, the slope height, the actual sliding distance (La) of the Shuicheng landslide, and the calculated maximum and minimum values of Ls are obtained in the following Table 1.

Table 1. Comparison of the sliding distance obtained by empirical formula and the actual sliding distance.

\begin{tabular}{cccccc}
\hline Data Sources & $\begin{array}{c}\text { Source Area } \\
\left(\mathbf{m}^{\mathbf{2}}\right)\end{array}$ & $\begin{array}{c}\text { Slope Height } \\
(\mathbf{m})\end{array}$ & $\begin{array}{c}\text { Actual Sliding } \\
\text { Distance } \mathbf{( m )}\end{array}$ & $\begin{array}{c}\text { Maximum of Empirical } \\
\text { Sliding Distance }(\mathbf{m})\end{array}$ & $\begin{array}{c}\text { Minimum of Empirical } \\
\text { Sliding Distance }(\mathbf{m})\end{array}$ \\
\hline Ma et al. (2020) [19] & 45,000 & 500 & 1400 & 1974.219148 & 1190.261406 \\
Gao et al. (2020) [13] & 48,000 & 460 & 1430 & 1830.164032 & 1103.410235 \\
$\quad$ Obtained from & 33,200 & 480 & 1300 & 1828.455738 & 1102.3803 \\
Google Earth & & & & \\
\hline
\end{tabular}

By comparison, the actual sliding distance (La) of the Shuicheng landslide is between the calculated maximum and minimum values of the empirical one (Ls), indicating that the empirical prediction formula can be perfectly applied in the area around the Shuicheng landslide. Similar to the Shuicheng landslide, the original ancient landslide may be destabilized once again to form a new landslide, and the entire ancient landslide body may become the landslide source area in the future. According to the statistics of regional ancient landslides, the largest and smallest landslides in the study area respectively possess areas of $\mathrm{S}_{1}=3,711,230 \mathrm{~m}^{2}$ and $\mathrm{S}_{2}=1404 \mathrm{~m}^{2}$, and slope heights of $\mathrm{H}_{1}=528 \mathrm{~m}$ and $\mathrm{H}_{2}=25 \mathrm{~m}$. Based on the empirical formula, $\mathrm{L}_{1}$ is between 2115.4 and $3508.7 \mathrm{~m}$, and $\mathrm{L}_{2}$ is between 39.5 and $65.6 \mathrm{~m}$. Therefore, when building houses, schools, and other important building facilities in the study area, we suggest that the area within $\approx 3500 \mathrm{~m}$ from a potential landslide should be paid more attention and studied in detail to avoid landslide hazards.

\section{Conclusions}

(1) The Shuicheng landslide is a high-level and long-runout landslide with an elevation difference of $480 \mathrm{~m}$ and a horizontal movement distance of $1300 \mathrm{~m}$. The slope dips at the northeast direction with a slope angle of $25^{\circ}$. These landform features accord well with the geomorphological characteristics of the landslide-prone places based on the dataset of 1158 ancient landslides in this area by 3D and spatial analyst tools in ArcGIS. The stratigraphic structure of the landslide in the boreholes shows the movement process of the landslide diversion and the original geomorphic form, and meanwhile, it reveals that the Shuicheng landslide is regenerated by an ancient landslide. 
(2) Based on comprehensive analysis, the strong tectonic activity results in the formation of high terrain and steep slopes, and it breaks the bedrock joints under subsequent weathering, providing conditions for the occurrence of landslides. Additionally, the rainfall lasting several days increases the hydrostatic pressure of groundwater, slope load, and sliding force and consequently reduces the rock water-saturated layer exerted by lubrication effect and loses the base friction. Under such circumstances, rock masses on the slope are easier to slide farther, causing greater damage in the local area.

(3) Previous empirical prediction formula of sliding distance from Corominas (1996) has been verified to meet the actual situation in the study area by the Shuicheng landslide parameters. Therefore, the area within $\approx 3500 \mathrm{~m}$ away from the risk source (the ancient landslides) is suggested to be concerned and studied during engineering constructions in the study area, which is probably the available landslide risk management measure of the area.

Author Contributions: Conceptualization, Xiangli He and Chong Xu; methodology, Yu Chen; software, Yuandong Huang; validation and formal analysis, Xiangli He, Chong $\mathrm{Xu}$, Yu Chen and Zhihua Luo; investigation, Pengfei Zhang and Tao Zhan; resources, Xiangli He; data curation, Chong Xu; writing_-original draft preparation, Yu Chen; writing—review and editing, Xiangli He and Chong $\mathrm{Xu}$; visualization, $\mathrm{Yu}$ Chen; supervision, Chong $\mathrm{Xu}$; project administration, Xiangli He; funding acquisition, Xiangli He and Chong $\mathrm{Xu}$. All authors have read and agreed to the published version of the manuscript.

Funding: This research was funded by the National Natural Science Foundation of China, grant number 42002225, the research project of Key Laboratory of Deep-Earth Dynamics of Ministry of Natural Resources, grant number J1901, and the Lhasa National Geophysical Observation and Research Station, grant number NORSLS20-07.

Institutional Review Board Statement: Not applicable.

Informed Consent Statement: Not applicable.

Data Availability Statement: The data presented in this study are available on request from the corresponding author. The data are not publicly available due to our database is under construction.

Conflicts of Interest: The authors declare no conflict of interest.

\section{References}

1. Rong, G.Z.; Li, K.W.; Han, L.N.; Alu, S.; Zhang, J.Q.; Zhang, Y.C. Hazard Mapping of the Rainfall-Landslides Disaster Chain Based on GeoDetector and Bayesian Network Models in Shuicheng County, China. Water 2020, 12, 2572. [CrossRef]

2. Rong, G.Z.; Alu, S.; Li, K.W.; Su, Y.L.; Zhang, J.Q.; Zhang, Y.C.; Li, T.T. Rainfall Induced Landslide Susceptibility Mapping Based on Bayesian Optimized Random Forest and Gradient Boosting Decision Tree Models-A Case Study of Shuicheng County, China. Water 2020, 12, 3066. [CrossRef]

3. Ma, S.Y.; Xu, C.; Shao, X.Y.; Xu, X.W.; Liu, A.C. A large old landslide in Sichuan Province, China: Surface displacement monitoring and potential instability assessment. Remote Sens. 2021, 13, 2552. [CrossRef]

4. Cui, Y.L.; Hu, J.H.; Xu, C.; Zheng, J.; Wei, J. A catastrophic natural disaster chain of typhoon-rainstorm-landslide-barrier lake-flooding in Zhejiang Province, China. J. Mt. Sci. 2021, 18, 2108-2119. [CrossRef]

5. He, X.L.; Xu, C.; Qi, W.W.; Huang, Y.D.; Cheng, J.; Xu, X.W.; Yao, Q.; Lu, Y.K.; Dai, B.Y. Landslides triggered by the 2020 Qiaojia Mw 5.1 Earthquake, Yunnan, China: Distribution, influence factors and tectonic significance. J. Earth Sci. 2021, 32, 1056-1068. [CrossRef]

6. Li, H.; Shi, W.B.; Zhu, Y.Q.; Peng, X.W. Study on the formation mechanism of "7.23" catastrophic landslide in Shuicheng County, Guizhou Province, China. J. Nat. Disasters 2020, 29, 188-198. (In Chinese)

7. Lian, X.G.; LI, Z.J.; Yuan, H.V.; Liu, J.B.; Zhang, Y.J.; Liu, X.Y.; Wu, Y.R. Rapid identification of landslide, collapse and crack based on low-altitude remote sensing image of UAV. J. Mt. Sci. 2020, 17, 2915-2928. [CrossRef]

8. Han, J.L. The Identification of Large-Giant Bedrock Landslides Triggered by Earthquake in the Longmenshan Tectonic Belt. Acta Geol. Sin. 2015, 89, 681-682.

9. Jiao, Q.S.; Jiang, W.L.; Li, Q. Research on mechanism and process of the Shuicheng landslide in Guizhou based on UAV images. In Proceedings of the International Geoscience and Remote Sensing Symposium, Waikoloa, HI, USA, 26 September-2 October 2020.

10. Zheng, G.; Xu, Q.; Liu, X.W.; Li, Y.C.; Dong, X.J.; Ju, N.P.; Guo, C. The Jichang landslide on 23 July 2019 in Shuicheng, Guizhou: Characteristics and failure mechanism. J. Eng. Geol. 2020, 28, 541-556. (In Chinese) 
11. Fan, X.Y.; Tang, J.J.; Tian, S.J.; Jiang, Y.J. Rainfall-induced rapid and long-runout catastrophic landslide on 23 July 2019 in Shuicheng, Guizhou, China. Landslides 2020, 17, 2161-2171. [CrossRef]

12. Li, H.B.; Xu, Y.R.; Zhou, J.W.; Wang, X.K.; Yamagishi, H.; Dou, J. Preliminary analyses of a catastrophic landslide occurred on 23 July 2019, in Guizhou Province, China. Landslides 2020, 17, 719-724. [CrossRef]

13. Gao, H.Y.; Gao, Y.; He, K.; Li, B.; Zhao, Z.N.; Chen, L.C.; Wang, Y.F. Impact and scraping effects of the high-elevation, long-runout "7.23" landslide in Shuicheng, Guizhou. Carsologica Sin. 2020, 39, 535-546. (In Chinese)

14. Xia, G.Q.; Liu, C.; Xu, C.; Le, T.C.; Foong, L. Dynamic Analysis of the High-Speed and Long-Runout Landslide Movement Process Based on the Discrete Element Method: A Case Study of the Shuicheng Landslide in Guizhou, China. Adv. Civ. Eng. 2021, 2021, 8854194. [CrossRef]

15. Chen, X.Z.; Cui, Y.F. The formation of the Wulipo landslide and the resulting debris flow in Dujiangyan City, China. J. Mt. Sci. 2017, 14, 1100-1112. [CrossRef]

16. Yan, Y.P.; Liu, C.Z.; Chen, H.Q.; Ren, J.; Zhu, C.B. Investigation on catastrophic landslide of 11 January 2013 at Zhaojiagou, Zhenxiong county, Yunnan province. J. Eng. Geol. 2013, 21, 6-15. (In Chinese)

17. Liu, C.Z. Landslide disaster in Lidong Village, Yaxi Town, Liandu District, Lishui City, Zhejiang Province. Chin. J. Geohazard. Prev. 2015, 26, 5. (In Chinese)

18. Zhao, W.H.; Wang, R.; Liu, X.W.; Ju, N.P.; Xie, M.L. Field survey of a catastrophic high-speed long-runout landslide in Jichang Town, Shuicheng County, Guizhou, China, on 23 July 2019. Landslides 2020, 17, 1415-1427. [CrossRef]

19. Ma, S.Y.; Xu, C.; Xu, X.W.; He, X.L.; Qian, H.T.; Jiao, Q.S.; Gao, W.; Yang, H.N.; Cui, Y.L.; Zhang, P.F.; et al. Characteristics and causes of the landslide on 23 July 2019 in Shuicheng, Guizhou Province, China. Landslides 2020, 17, 1441-1452. [CrossRef]

20. Du, X.L.; Peng, F.; Lan, W.; Zhang, Y.M.; Zhu, Y.L. Analysis of precipitation background of "7.23" Shuicheng landslide. Torrential Rain Disasters 2020, 39, 344-353. (In Chinese)

21. Zhang, Y.B.; Xing, A.G.; Jin, K.P.; Zhuang, Y.; Bilal, M.; Xu, S.M.; Zhu, Y.Q. Investigation and dynamic analyses of rockslideinduced debris avalanche in Shuicheng, Guizhou, China. Landslides 2020, 17, 2189-2203. [CrossRef]

22. Caracciolo, D.; Arnone, E.; Conti, F.; Noto, L. Exploiting historical rainfall and landslide data in a spatial database for the derivation of critical rainfall thresholds. Environ. Earth Sci. 2017, 76, 1-16. [CrossRef]

23. Iverson, R.M. Landslide triggering by rain infiltration. Water Resour. Res. 2020, 36, 1897-1910. [CrossRef]

24. Li, W.C.; Dai, F.C.; Wei, Y.Q.; Wang, M.L.; Min, H.; Lee, L.M. Implication of subsurface flow on rainfall-induced landslide: A case study. Landslides 2015, 13, 1109-1123. [CrossRef]

25. Lamens, P.; Askarinejad, A. Pile driving and submarine slope stability: A hybrid engineering approach. Landslides 2021, 18, 1351-1367. [CrossRef]

26. Zhan, J.N.; Zhou, Z.; Lin, F.; Yang, Q.G.; Luo, Y. Failure mechanism of a slow-moving landslide on 27 September 2020 , in Chang Nong Village, Guangxi, China. Landslides 2021, 18, 2575-2592. [CrossRef]

27. Wang, Y.; Zhao, B.; Li, J. Mechanism of the catastrophic June 2017 landslide at Xinmo Village, Songping River, Sichuan Province, China. Landslides 2017, 15, 333-345. [CrossRef]

28. Wen, B.; Wang, S.; Wang, E.; Zhang, J. Characteristics of rapid giant landslides in China. Landslides 2004, 1, 247-261. [CrossRef]

29. Ma, S.; Xu, C.; Shao, X.; Zhang, P.; Liang, X.; Tian, Y. Geometric and kinematic features of a landslide in Mabian Sichuan, China, derived from UAV photography. Landslides 2019, 16, 373-381. [CrossRef]

30. Yin, Y.; Cheng, Y.; Liang, J.; Wang, W. Heavy-rainfall-induced catastrophic rockslidedebris flow at Sanxicun, Dujiangyan, after the Wenchuan Ms 8.0 earthquake. Landslides 2016, 13, 9-23. [CrossRef]

31. Abe, S.; Tien, D.; Ngoc, H.D.; Hoshide, T.; Nishitani, T.; Miyagi, T. Topography and landslides in weathered granitic rock areas-Hai Van landslide in central Vietnam. Landslides 2018, 15, 1675-1689. [CrossRef]

32. Wang, Y.; Jin, J.L.; Yuan, R.M. Analysis on Spatial Distribution and Influencing Factors of Geological Disasters in Southeast Tibet. J. Seismol. Res. 2019, 42, 198-199.

33. Roy, S.; Baruah, A.; Misra, S.; Mandal, N. Effects of bedrock anisotropy on hillslope failure in the Darjeeling-Sikkim Himalaya: An insight from physical and numerical models. Landslides 2015, 12, 927-941. [CrossRef]

34. Louise, M.; Martina, B.; Line, R.; Steffen, G.B.; Geoffre, D.C.; Tom, R.L. Structurally controlled rock slope deformation in northern Norway. Landslides 2020, 17, 1745-1776.

35. Rabby, Y.W.; Li, Y.K. An integrated approach to map landslides in Chittagong Hilly Areas, Bangladesh, using Google Earth and field mapping. Landslides 2019, 16, 633-645. [CrossRef]

36. Siyamack, S.; Mohsen, E.M.; Soheilnaz, D. Mechanism of landslide damming in Morzarrin Valley and its consequences, Lorestan Province, western Iran. Landslides 2021, 18, 1823-1832.

37. Xu, C. Preparation of Earthquake-Triggered Landslide Inventory Maps Using Remote Sensing and GIS Technologies: Principles and Case Studies. Geosci. Front. 2015, 6, 825-836. [CrossRef]

38. Panday, S.; Dong, J.J. Topographical features of rainfall-triggered landslides in Mon State, Myanmar, August 2019: Spatial distribution heterogeneity and uncommon large relative heights. Landslides 2021, 18, 3875-3889. [CrossRef]

39. Youssef, A.M.; Pourghasemi, H.R.; Pourtaghi, Z.S.; Al-Katheeri, M.M. Landslide susceptibility mapping using random forest, boosted regression tree, classification and regression tree, and general linear models and comparison of their performance at Wadi Tayyah Basin, Asir Region, Saudi Arabia. Landslides 2016, 13, 839-856. [CrossRef] 
40. Xu, C.; Xu, X.W.; Yao, X.; Dai, F.C. Three (Nearly) Complete Invento-ries of Landslides Triggered by the 12 May 2008 Wenchuan Mw7.9 Earthquake of China and Their Spatial Distribution Statistical Analysis. Landslides 2014, 11, 441-461. [CrossRef]

41. Corominas, J. The angle of reach as a mobility index for small and large landslides: Reply. Can. Geotech. J. 1996, 33, 1029-1031. [CrossRef]

42. Xu, C.; Xu, X.W.; Tian, Y.Y.; Shen, L.L.; Yan, Q.; Huang, X.Q.; Ma, J.X.; Chen, X.; Ma, S.Y. Two Comparable Earthquakes Produced Greatly Different Coseismic. Landslides: The 2015 Gorkha, Nepal and 2008 Wenchuan, China Events. J. Earth Sci. 2016, 27, 1008-1015. [CrossRef]

43. Ma, C.; Xie, Z.M.; Li, M. Types and hazard levels of Nanshan landslides at the junction of Yushibulake Village and Qapuhe Awuzi Village, Xinyuan County, Xinjiang. Xinjiang Nonferrous Met. 2021, 44, 26-27. (In Chinese)

44. Ma, S.; Shao, X.; Xu, C.; He, X.; Zhang, P. MAT.TRIGRS (V1.0): A new open-source tool for predicting spatiotemporal distribution of rainfall-induced landslides. Nat. Hazards Res. 2021. [CrossRef]

45. Guo, J.; Yi, S.J.; Yin, Y.Z.; Cui, Y.F.; Qin, M.Y.; Li, T.L.; Wang, C.Y. The effect of topography on landslide kinematics: A case study of the Jichang town landslide in Guizhou, China. Landslides 2020, 17, 959-973. [CrossRef]

46. Li, S.S.; Li, G.P.; Wang, X.F.; Li, C.; Liu, H.Z.; Li, G. Precipitation Characteristics of an Abrupt Heavy Rainfall Event over the Complex Terrain of Southwest China Observed by the FY-4A Satellite and Doppler Weather Radar. Water 2020, 12, 2502. [CrossRef]

47. Liu, X.L.; Chen, X.; Su, M.; Zhang, S.L.; Lu, D.F. Stability Analysis of a Weathered-Basalt Soil Slope Using the Double Strength Reduction Method. Adv. Civ. Eng. 2021, 2021, 6640698. [CrossRef]

48. Zhou, J.W.; Li, H.B.; Lu, G.D.; Zhou, Y.; Zhang, J.Y.; Fan, G. Initiation mechanism and quantitative mass movement analysis of the 2019 Shuicheng catastrophic landslide. Q. J. Eng. Geol. Hydrogeol. 2020, 54, 1-12. [CrossRef]

49. Parker, R.N.; Densmore, A.L.; Rosser, N.J. Mass wasting triggered by the 2008 Wenchuan earthquake is greater than orogenic growth. Nature 2011, 4, 449-452. [CrossRef] 